\title{
Paradoxes in the Management of Timebanks in the UK's Voluntary Sector: Discursive Bricolage and its Limits
}

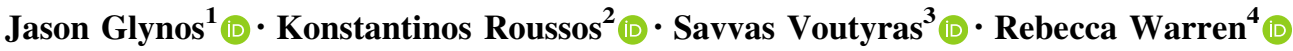

Accepted: 23 January 2022

(C) The Author(s) 2022

\begin{abstract}
This paper contributes to our understanding of volunteer management by charting some important challenges associated with the governance of one of the UK's largest timebanking networks. While timebanking is often treated as a form of volunteering, many timebank advocates are keen to distinguish it sharply from traditional volunteering. We suggest that this tension generates a fundamental 'performance paradox' in the management of timebanks in the voluntary sector. We draw on political discourse theory to characterise and evaluate associated challenges, suggesting that, when viewed against a host of context-specific organisational and policy pressures, the progressive potential of timebanking cannot be realised as a distinct community economy without adequate support. Instead of taking up a position alongside more traditional forms of volunteering, timebanking is more likely to be subsumed by them.
\end{abstract}

Jason Glynos

ljglyn@essex.ac.uk

Konstantinos Roussos

k.roussos@essex.ac.uk

Savvas Voutyras

svoutyras@bournemouth.ac.uk

Rebecca Warren

rw17735@essex.ac.uk

1 Department of Government, University of Essex, Colchester, UK

2 School of Health and Social Care, University of Essex, Colchester, UK

3 Department of Humanities and Law, Bournemouth University, Bournemouth, UK

4 Essex Business School, University of Essex, Colchester, UK
Keywords Political discourse theory - Timebanks · Volunteer management $\cdot$ Paradox $\cdot$ Discursive bricolage

\section{Introduction}

Timebanking is a community economy in which people exchange tasks or 'services' using labour time as currency (Seyfang, 2002). For example, one hour's worth of decorating can be 'banked', and then exchanged for one hour's worth of computer tuition or shopping assistance. A unique feature of this community economy, as compared to the market economy, is that all labour time is valued equally. The timebank community emerges out of a network of such exchanges and, since 1982, when Edgar Cahn first developed the idea of 'time credits', timebanking has attracted the interest of scholars, third sector organisations, policy makers, and state institutions, on account of its potential to build community and mutual support capacity, and to promote social inclusion (Cahn, 2000).

Although timebanking was introduced into the UK in 1998 , it is still considered rather novel, and its growth and spread has been understood as a response primarily to social exclusion and as a way to imbue public service provision with an ethos of reciprocity or 'co-production' (Glynos \& Speed, 2012; Ryan-Collins et al., 2008; Seyfang \& Smith, 2002). In this context, timebanking has been mobilised to draw people who feel isolated into networks of exchange, often jointly with statutory authorities and third sector organizations-e.g. older people, the unemployed, differently abled, or recently discharged hospital patients. Thus, a range of timebanking practices have emerged across the UK (Naughton-Doe et al., 2020), where they tend to be treated as a new form of volunteering. A distinction has thus emerged in associated UK volunteering 
policy and practice, between two sorts of volunteering: 'timebank volunteering' on the one hand, and the more familiar 'traditional' forms of volunteering on the other.

It is this timebank/traditional volunteering 'doublet' that sets the context of our research problem because data suggests that non-trivial tensions and paradoxes emerge when these distinct forms of volunteering meet. According to some timebank advocates, for example, traditional forms of volunteering are less reciprocal in character becausedespite the wide range of motivations that underpin such engagements - some individuals dominate the 'offering' of a service, while a distinct set of individuals in need dominate the 'receiving' of a service. Our research thus focuses on the question how best to conceptualize the challenges of managing timebank volunteers in a context dominated by forms of traditional volunteering, and our aim is to develop an appropriate framework and language within which to undertake this characterization exercise.

In what follows, we begin with a brief overview of how such paradoxes and tensions appear in our case study, explaining why they matter. We then consider how key contributions in the literature on timebanking and the management of volunteers help illuminate the character and significance of these paradoxes and tensions. While valuable, we argue that existing conceptual resources can be usefully supplemented by turning to political discourse theory (Glynos \& Howarth, 2007; Laclau \& Mouffe, 1985), in particular the notions of discourse, articulation, and 'onto-political interpretation'. After outlining our methods and corpus, we characterize and problematize the social practices comprising the management of volunteers in our case study, rendering visible the logics that make it difficult for timebanking norms to take root. In this way we showcase the daunting challenges faced by agents seeking to translate the potential of timebank volunteering into meaningful community empowerment. By reconceiving the role of timebank volunteer managers as discursive bricoleurs, we suggest that these challenges can be usefully characterized in terms of a set of wider discursive structures. We argue that a number of dominant and dominating structures converge to produce a hostile environment for timebank volunteer managers, tilting the power balance towards a more widespread reimposition of traditional forms of volunteering, albeit in the name of timebank volunteering. Such structures can be understood as a function of the traditional volunteering signifying frame itself; but also as a function of a host of other signifying frames associated with: state service provision; hierarchical governance structures; funding and monitoring imperatives associated with the legacy of austerity Britain; as well as competitive individualism and market exchanges. Although all five of the above-mentioned structures play an important role in understanding the challenges associated with the management of timebank volunteers in the political-economic context of the UK, our paper deals primarily with the challenges thrown up for timebanking on account of the signifying frame of traditional volunteering.

\section{The Performance Paradox: A Fundamental Challenge in the Management of Timebank Volunteers}

When asked what they consider to be the main challenge to the promotion and establishment of timebanking, there was little hesitation from timebank managers in our focus group: 'timebanking can be quite difficult to explain'; 'it can be very, very difficult for some people to grasp'; 'you can spend a lot of time explaining it to charities, organisations, certain people' (FG1). But one thing was also clear in their responses: timebanking is distinct from traditional volunteering, even though what this difference amounts to was not always clear-cut. To meet this explanatory challenge, managers turn to a host of creative rhetorical devices: '[W]e all have our own techniques and ways of explaining it' (FG1). For example, in explaining the concept to (new) volunteers they might begin by saying that timebanking is 'volunteering with a twist', or 'your own way' of doing volunteering. What becomes clear in their accounts of the challenges associated with the recruitment of timebanking volunteers is how the idea and practice of timebanking is not 'natural', demanding considerable work on the part of managers to make timebanking both understandable and viable. In a real sense, then, the discursive labour expended by managers is designed to bring timebanking - its members and practice - into existence. Timebank managers thus confront an odd paradox: they are called on to manage practices - and subjects therein - that often do not yet exist.

We argue that this paradox is fundamental to the institutionalisation of timebanking, especially within an environment dominated by other signifying frames, such as traditional understandings of volunteering. We call this the performance paradox of timebanking volunteer management because the (rhetorical) performance of the manager brings into existence what s/he purportedly is supposed to manage. Thus, our paradox is constructed in the interval between being and becoming, the space between reality and possibility. This understanding of paradox differs markedly from the way it tends to be conceptualized in the literature, namely, as contradictory dualities that exist and persist within an organisational whole (e.g. Smith \& Lewis, 2011). Our formulation of the paradox in discursive terms also goes some way to explaining the challenges associated with timebank volunteering that managers express. In particular, it accounts for the non-trivial discursive labour 
involved: performatively bringing something into existence demands considerable time and effort. This is, in part, because the 'birthing' process comes with understandable signifying tensions that coordinators seek to manage. For example, their discursive labour might entail drawing appropriate context-specific analogies and distinctions: timebanking is like (traditional) volunteering in some respects (e.g. engaging in an activity benefitting someone); and not like (traditional) volunteering in other respects (e.g. it is about generalised reciprocal skill-sharing). These tensions are clearly discursive in character, calling on managers to both produce new signifying boundaries and manage meaning effects.

In some sense, the signifying tensions produced by the introduction of timebanking into an already established ecology of traditional volunteering should not be surprising. The taking root of any new practice, of which timebanking is one example, involves seeing it as a process of 'becoming': a fragile affair demanding considerable care, effort, and time (Connolly, 2010). But the idea and practice of timebanking is vulnerable not only to the weighty influence of the dominant logics of traditional volunteering. As we briefly alluded to above, it can also be pulled into the gravitational field of spheres animated by other logics, such as the logics of state service provision or market commodities. Therefore we argue that timebank managers should be understood as 'discursive bricoleurs' who must not only engage actively in an exercise of 'onto-political interpretation' (explained below), in which new subjects and practices are brought into being, but also take seriously the need to make important normative and strategic judgements. Such judgements are important to thematise in our analysis because they are the way timebank managers handle tensions emerging out of the fundamental performance paradox we identify. Thematising such judgement junctures is important from a critical perspective too, and, to help us see this clearly, we identify a set of two 'secondary' paradoxes articulated in the case material. In our concluding discussion we show how the broader accountability and governance context in our case study serves to exacerbate rather than alleviate the challenges faced by volunteer managers. In what follows, before we lay out the two secondary paradoxes, we make explicit why it is worth understanding these paradoxes and the tensions they index as discursive phenomena, not least because doing so enables us to see more clearly their ontological, political, and ideological import. We also present an overview of our case study and methodology. To begin with, however, we explore how the literature has sought to characterize timebanking and the challenges of managing volunteers more generally.

\section{Rethinking the Tensions and Paradoxes of Timebanking in Terms of the Management of Volunteers}

In this section we bring together timebanking and organisation studies literature. We find that although the timebanking literature is extremely helpful in setting out the difference between timebanking and traditional volunteering, it does not emphasise the challenges these differences generate from the point of view of management in the voluntary sector. Moreover, while critical management and organisation studies literature offers very important critical insights as regards management practices across a wide range of organisational settings, tensions and paradoxes in the management of volunteers remain under-studied in general; and they are not studied at all in relation to the management of timebanking in the voluntary sector.

\section{Timebanking}

Timebanking 'creates a reciprocal relationship between people and institutions as well as people and people' that allows even marginalized and socially excluded members of the society 'to give something back, to make a contribution and feel needed' (Boyle, 1999, 29). Embodying the values of co-production and reciprocity, timebanking engages participants in voluntary social work not simply as beneficiaries or users 'in need', but also-perhaps especially — as active participants, offering a way to extend and deepen social inclusion in an empowering manner (North, 2003). Viewed as a social economy innovation, the rewarding character of timebank participation points to its potential in fostering reciprocity and equality in ways that traditional volunteering would not.

Moreover, and importantly from the perspective of our investigation, Gregory (2012) notes how notions of traditional volunteering can have a detrimental effect on timebank members' outlook and thus on timebanking exchanges. For example, a number of researchers have found that often members are reluctant to ask for help, but happy to offer help, thus placing a limit on the number of exchanges that occur (Ozanne, 2010; Seyfang \& Smith, 2002). Researchers have also found that members might not offer to do anything for someone because they find it difficult to identify a skill or service that they think others would value (Oppenheimer, 2011), or members hoard time credits, stifling the potential for reciprocal exchanges and creating pressures to engage in activities that look more like traditional volunteering, rather than timebanking activities (Gregory, 2013). Researchers therefore warn that without putting in place appropriate measures, members lose interest (Boyle \& Smith, 2005; Warne \& Lawrence, 
2009), a loss of interest often exacerbated due to the imposition of onerous bureaucratic strictures and/or because skill-need matches are not made quickly enough (Feder et al, 1992). While these present timebank advocates and practitioners with obstacles to overcome, some scholars argue that many of these problems emerge because timebanking's underlying philosophy and value system are not sufficiently understood by members (Lee, 2009).

Existing timebanking research thus offers us valuable insights, particularly as regards the differences between timebanking and traditional volunteering. In this view, the emphasis in traditional volunteering is placed on satisfying the needs of individuals and communities by mobilising the good will and skills of other individuals. In the case of timebank volunteering, on the other hand, individuals and communities are treated in what advocates call "co-productive' terms: less in terms of needs of one set of individuals and the skills of another set of individuals, and more in terms of a mix of abilities and needs shared across all individuals in a generalized network of exchanges. However, the timebanking literature does not explore in detail the character of the paradoxes that these differences in the understanding of volunteering produce, nor how their management can or should be characterised. To better understand these elements of our puzzle, we turn first to organisation and critical management studies literature, before we introduce our own perspective.

\section{Managing Volunteers}

Volunteering can accommodate a wide variety of motivations (Omoto et al., 2000), motivation-determining factors (Salamon and S.W. Sokołowski 2001), and types (Smith, 2000). Indeed, in organisation studies literature several scholars have explored the character of volunteer motivation in some detail, arguing that we should replace overly simplistic, one-dimensional accounts of motivation with more complex, multiple, context-sensitive ones (Barron \& Rihova, 2011). As noted earlier, we treat traditional volunteering and timebanking volunteering as two types of volunteering that can each accommodate an internal pluralism made up of a wide range of motivations. The focus of our paper, however, is less on the motivational variety per se, and more on the tensions and paradoxes this variety generates. Indeed scholars have already noted how this variety and complexity in motivation can become a source of paradoxes (la Cour, 2019; O'Toole \& Grey, 2016). For example, la Cour and Højlund $(2008,41)$ characterise voluntary social care as paradoxical, in the sense that there is an impossible compromise between interactional and organisational logic' in such space that should not be dissolved or resolved, but instead should be drawn on productively and dynamically.

However, although some such very interesting paradoxrelated observations appear in the literature (see, Jäger et al., 2009; Yanay \& Yanay, 2008; O’Toole \& Grey, 2016; Clemens \& Cook, 1999) there is less focus on the paradoxes involved in the management of volunteers, by which is meant not only how certain given motivations and other associated elements can be aligned or managed when brought into contact with one another in a particular context, but also how they are transformed and generated in the process of volunteer management and engagement itself. Moreover, while scholars have also drawn attention to a notable dearth in the literature exploring the challenges faced by managers of volunteer organisations in the care and community sectors (Barnes \& Sharpe, 2009; Kreutzer, \& Jäger, 2011; Le Cour, 2019), our own research focuses on the paradoxes and tensions that emerge in the management of timebanking in a context dominated by the signifying frame of traditional volunteering, about which the literature does not have much to say.

\section{Advancing the Debate}

Still, since scholars argue that appreciating the character of such paradoxes is important for academics and progressively minded volunteer managers (Lewis, 2000; Smith \& Lewis, 2011), it is instructive to consider what the literature says about paradoxes in management practices more generally (Weatherbee et al., 2008). While the understanding of paradox is rather malleable and varies across this literature, Smith and Lewis $(2011,382)$ provide a definition that can be treated as indicative. In this view paradoxes incorporate '[c]ontradictory yet interrelated elements that exist simultaneously and persist over time'. Sometimes paradoxes generate tensions that are understood to be problematic, demanding their elimination or mitigation, and sometimes paradoxes are understood to be ineliminable and even necessary, with the task of management amounting to finding ways to navigate them (Grubb \& Henriksen, 2019; la Cour, 2019; Smith \& Lewis, 2011).

The Smith and Lewis definition is useful for two reasons. First, it shows us that many paradoxes and tensions discussed in the volunteering management literature can be captured by this definition. In fact, our own case study provides plenty of empirical evidence that supports the existence and persistence of such paradoxes, inviting managers to find ways of navigating the tensions they embody. In this paper, however, we do not touch directly on these paradoxes, partly for reasons of space. And this brings us to the second reason Smith and Lewis serves as a convenient reference point for us. This is because we focus on features in our case study which have helped us identify 
the existence of a paradox that departs in a significant way from their formulation, denoting not tensions emerging due to given contradictory elements that exist simultaneously and persistently within a system, but rather tensions of an indeterminate character, suspended between the being of presently existing dominant practices and the becoming of future alternative ones. We believe that our formulation of the paradox is crucial not only in understanding some of the tensions experienced by timebank volunteer managers, but also in appreciating the political and ideological significance of this management practice.

As is perhaps evident in the earlier description of the 'performative paradox', what is under-emphasised and under-theorised in the Smith and Lewis picture is the constitutive role of discursive articulation in both the appearance and negotiation of tensions associated with such management paradoxes. In other words, these tensions and paradoxes are of a simultaneous dynamic and discursive character. Moreover, introducing the idea of a 'performance paradox' allows us to better appreciate the political and ideological consequences of introducing timebanking into a context dominated not only by traditional volunteering norms, but also by other dominant (and dominating) accountability and governance norms linked to valuation techniques, participatory ideals, and empowerment talk, which other scholars have powerfully sought to foreground on account of the latter's tendency to co-opt progressive initiatives (Eliasoph, 2011; Meriluoto, 2019; Glynos \& Voutyras, forthcoming 2022). We take seriously the cooptation worries of such authors, seeking to make their insights relevant to the debate about the paradox of volunteer management we outline. To our knowledge there is no literature focussing on the paradoxes, signifying tensions, and normative dilemmas associated with the management of timebanking volunteers in particular. Our paper, therefore, contributes to this literature by focussing on the tensions underlying the management of different sorts of volunteering activities, paying special attention to timebank volunteering and its relation to traditional volunteering.

\section{Theory, Data, Methods}

As we noted above, the analytical focus of the timebanking literature tends to be less the management of timebanking volunteers than the timebanking practice itself. But this observation already suggests that management dilemmas might be grasped through the idea of 'misunderstanding' i.e. that management dilemmas can be resolved by better clarifying what we mean by timebank volunteering, as opposed to traditional volunteering. The problem with this perspective, however, is that it presupposes a particular theory of meaning that underplays the constitutive role of discursive struggle. In other words, the source of misunderstanding may not be reducible to an analytical-conceptual problem: it may also signal the presence of an ontological and political problem. We thus draw on political discourse theory (PDT) to unpack these discursive tensions and paradoxes, showing how they can be exacerbated when they become overdetermined by other tensions and logics linked to funding imperatives, monitoring procedures, and governance processes. It is notable that PDT is an approach that has already received considerable attention in the field of critical management and organisation studies (see, Fougère et al., 2017; MacKillop, 2017), yet it is striking that its potential in capturing practices of management as both meaningful and political remains untapped when it comes to the domain of volunteer management, particularly as it relates to timebanking. In what follows, therefore, we set out some of the key categories of PDT, before outlining our fieldwork strategy and corpus.

\section{Discourse, Articulation, Onto-political Interpretation, and Discursive Bricolage}

'Discourse', in PDT, is an overarching concept capturing the character of social reality in a way that does not reduce it to language, in its linguistic sense:

Let us suppose that I am building a wall with another bricklayer. At a certain moment I ask my workmate to pass me a brick and then I add it to the wall. The first act - asking for the brick - is linguistic; the second - adding the brick to the wall - is extralinguistic [...] [Yet] despite their differentiation [...] the two actions share something that allows them to be compared, namely the fact that they are both part of a total operation which is the building of the wall [...] this totality which includes within itself the linguistic and the non-linguistic, is what we call discourse (Laclau \& Mouffe, 1987, 82)

Discourse, therefore, represents an ontological horizon comprising both linguistic and non-linguistic elements which can be linked together through what Laclau and Mouffe call articulation: 'any practice establishing a relation among elements such that their identity is modified as a result of the articulatory practice' $(1985,105)$. Articulation is thus a process pregnant with political potentiality, as it produces the meaning of objects and practices by establishing, dissolving, or transforming the links between them on the basis of certain normative assumptions and ideals.

PDT can be understood to belong to the family of political theories subscribing to a 'weak ontology' (White 2000), and sharing a commitment to what Connolly (1995, 
pp 1-2) calls an 'onto-political interpretation'. In this view, characterising practices is never a neutral exercise. It entails adopting certain normative and ideological commitments that are linked to political agency. Indeed, we would say that, in a social terrain permeated by contingency, rhetorical redescription is a key way in which agency is exercised (Glynos \& Howarth, 2007, p 196). Actors often replace 'a given evaluative description with a rival term that serves to picture the action no less plausibly, but serves at the same time to place it in a contrasting moral light. You seek to persuade your audience to accept your new description, and thereby to adopt a new attitude towards the action concerned' (Skinner in Howarth, 2010, p 319). For this reason, we argue that timebank managers can usefully be understood as discursive bricoleurs. As Laclau puts it, we 'live as bricoleurs in a plural world, having to take decisions within incomplete systems of rules' (Laclau, 1996, p 79). The aim of such discursive bricolage is, thus, to effect shifts in what we understand as 'common sense' by introducing novel organising principles and articulations of existing ideas and concepts. A key task for PDT researchers, therefore, is the identification of key 'moments of articulation', where practices-and their underlying norms - are either contested or defended. As we will see later, we present these 'moments of articulation' as competing onto-political interpretations, organising them around the paradoxes we identify in our empirical material.

Viewed against the background of PDT, timebank volunteering and traditional volunteering possess no necessary or 'essential' meaning. Instead, the meaning attributed to them by volunteers and managers alike emerge as a result of a practice of articulation taking place within contextspecific signifying frameworks and practices that influence these articulations. Our empirical investigation demonstrates the presence of such signifying structures and the challenges they present when managers seek to transform practices in a direction that embodies more closely the norms attributed to timebanking by its advocates.

\section{Case Background, Corpus, and Methods}

The timebanks that we focus on in this case study are part of a network of eleven timebanks across fourteen districts in a UK county. Each timebank has a coordinator-manager (the 'timebroker'), some responsible for more than one timebank. Some are volunteers and some are paid from funding secured by the lead organisation responsible for overseeing the network. Most timebanks are connected to community volunteer service centres, and often the timebank coordinator-manager has another role within the community centre, connected to the management of traditional volunteering. The role of the coordinator-manager involves a wide range of tasks, including stimulating and enabling exchanges and recording the number and character of transactions. In terms of management structure, therefore, coordinator-managers are placed directly above the timebank members and below the overseeing-managers. According to the agreements with the overseeingmanagers and the funders, each timebank activity has to meet regular monitoring requirements in the same way that traditional volunteering activities do, as well as specific targets set by overseeing-managers in the lead organisation, shaped in part by funders and other stakeholders. The targets can be a specific number of exchanges, recruitment of a certain number of new members, as well as increased exchanges of a specific type (e.g. linked to helping members facing isolation). The timebank network also holds quarterly meetings led by the overseeing-managers to discuss and share ideas and challenges across timebanks around operational, management, and funding issues.

Our corpus consists of data collected from timebank coordinator-managers, who comprise the main focus of our analysis, i.e. those who manage their respective timebanks and timebank members. Some coordinator-managers participated in multiple interviews. We collected data from two one-hour long semi-structured focus groups, and 16 1-h long semi-structured individual interviews, of which the majority were recorded and processed using Nvivo. Apart from holding regular meetings with the main network coordinators (overseeing-managers) throughout the research period, we also conducted site visits, including fourteen hours of observations, of which eight hours comprised observations of the quarterly timebank network meetings, the rest comprising general observations of timebank operations. Finally, we had access to relevant documentation, including monitoring reports, surveys, and case studies that timebank managers would collect to identify the impact of timebanking on its members. The data used in this article were collected as part of a research project that sought to identify and characterise the valuation methods used in this regional timebank network, and to understand the motives, experiences, and impacts associated with participant engagement in timebanking exchanges. As such, our research proceeded in a staged fashion, comprising: (1) initial meetings with the project managers of the lead organisation to identify the focus of the research; (2) visits and participatory observations of timebanking activities to investigate the diversity of practices and local assets in each timebank; (3) individual and focus group interviews with coordinator-managers to understand the organisation of each timebank and the tensions involved; and (4) online surveys and individual interviews with timebank members to further explore the character and impact of timebanking. The data were collected during 2019 and 2020, adding to an already sizeable 
data set and extensive research experience linked to timebanks in this region stretching back to 2009 .

\section{Main Findings and Analysis: Two Variations on the Performance Paradox Theme}

In this section we present our findings and analysis as a function of two 'offshoots' of the performance paradox we noted earlier. We recall that the performance paradox was conceptualized as a fundamental paradox for volunteer management because the (rhetorical) performance of the manager brings into existence what s/he purportedly is supposed to manage. Here, we show how each of the secondary paradoxes manifests itself in the self-interpretations of the coordinator-managers, and how each paradox condenses a series of tensions and dilemmas associated with the management of volunteers.

\section{Paradox 1: Everywhere but Nowhere}

The 'everywhere but nowhere' paradox describes a scenario in which timebanking has succeeded in expanding its reach and scope, but only at the expense of its being hollowed out. In this scenario, timebanking is ostensibly everywhere, largely on account of a reclassification exercise: traditional volunteering activity is reclassified as timebanking activity, and so timebanking now appears only in name.

We have already suggested how advocates of timebanking regard community building, reciprocity, co-production, skill sharing, and network exchanges as central to its logic. In an environment in which traditional volunteering is the 'main game in town', however, timebanking can be positioned as a counter-logic in the practice and organisation of voluntary social work. As we saw in our review of the timebanking literature, this is because the meaning attributed to timebanking by its advocates contrasts with dominant understandings of volunteering that emphasise the one-way-rather than reciprocal-nature of an exchange. As one coordinator-manager puts it, "timebanking was never supposed to be used with the word volunteering... [I]t was always meant to be 'just' timebanking... [V]olunteering was never meant to come into it" (Sarah, FG1). For this coordinator-manager volunteering is treated as synonymous with traditional volunteering. From this perspective traditional volunteering appears more like a one-way exchange, or gift: 'an intangible or tangible good or service (including the giver's time, activities and ideas) voluntarily provided to another person or group' (Booth et al., 2009, 230). It is thus clear that we are dealing here with a struggle over competing meanings:
"I don't know why they don't understand that it is kind of sharing of skills" says Michelle in a rather exasperated tone. According to her, the reciprocal character of timebanking is elided when it is treated as a form of (traditional) volunteering. "[Y]ou try to explain it, but some people just don't get it"; "you can spend a lot of time explaining it to charities, organisations, certain people" (Michelle, FG1).

From the perspective of PDT, coordinator-managers' attempts to 'operationalise' timebanking are effectively attempts to bring something new into being, a practice and experience that many people are not (yet) familiar with. This is why it is plausible to argue that coordinator-managers are engaged in no ordinary exercise of interpretation. In grappling with the limiting features and pathways of what is usually considered volunteering, they are engaged in labour-intensive exercises of onto-political interpretation: "[I]t's really hard to kind of get that concept [of timebanking] across" says Sarah (FG1). Managers are trying to bring into being something that does not yet exist, but in order to do so, they must act as discursive bricoleurs. For example, they may initially refer to experiences with which (new) participants or the broader community are familiar, in the hope that such 'moments of articulation' can serve as a bridge to new experiences.

The idea of 'volunteering with a twist' serves as one such rhetorical device. It enables coordinators to establish an entry point in their attempts to produce and recruit timebankers. As Danielle (FG1) notes: "we always call... [timebanking] 'volunteering with a twist'. And that's how we kick off conversations with people. It's not like regular volunteering [because] you've got the [reciprocal] exchange going, so that's quite a nice opener". The expression 'volunteering with a twist' appears natural in part because some coordinators manage not only timebank volunteers, but also traditional volunteers, in part because the people they are trying to recruit are operating in a context dominated by the signifying frame of traditional volunteering. As another focus group participant maintains, "if somebody comes to us and they say I want to do something, but I don't know what I want to do... we give them the choice of structured volunteering or timebanking' (Sarah, FG1). In this rhetorical bridging exercise managers begin to articulate traditional volunteering with something which is regular and long-term, while timebanking is articulated in a way that conveys something more 'ad hoc': "the thing with volunteering is that people usually have to agree to a particular time, a particular day, a particular length, whether it be a six weeks, month... With timebanking it's just ad hoc. [I]f you've got your weekends free and you want to go and help someone you can" (Laura, Interview). 
Evidently, coordinator-managers appreciate the difference between timebanking and volunteering. However, this awareness does nothing to diminish the challenge with which they are confronted. This is because the challenge here is not simply analytical-conceptual; as the expression 'onto-political interpretation' suggests, it is also ontological and political. It is ontological because the managers' discursive articulations and re-articulations do not amount simply to competing descriptions of something that already exists. Their interpretations serve to bring certain things into being in the first place. It is political because it is these certain things that are brought into existence and not others. In other words, such moments of articulation can take on distinct normative and ideological valences, resulting in different pathways of sedimentation. Under certain conditions, the scope of contingency associated with the process of articulation can be expanded; under other conditions it can be narrowed. For example, in a context dominated not only by the frame of traditional volunteering, but also by funding imperatives that demand ever-expanding numbers of timebank members and activities, coordinators will often promote timebanking as a more convenient 'plug-in' way of doing traditional volunteering (cf. Eliasoph, 2011: 117). The risk of introducing timebanking into such a context is that it gets stripped of the features its advocates prize: reciprocity, co-production, and mutuality. It risks producing the 'everywhere but nowhere' paradox, in which timebanking is 'everywhere' in name, but 'nowhere' in substance-a situation, in other words, in which traditional volunteering ends up masquerading as timebanking.

\section{Paradox 2: Nowhere but Everywhere}

In some sense the second paradox is the mirror image of the first one. It describes an ideal scenario in which the values of timebanking appear to have successfully installed themselves but its name and associated 'call to arms' are no longer seen as necessary. This paradox is most clearly expressed when timebank coordinator-managers note how once active timebank members cease to register their time credits they continue to engage in meaningful reciprocal exchanges. As one of our interviewees put it, "after a little while, we didn't hear from [our timebank members]; and when we contacted them, they said 'we've become friends now! We're not necessarily timebanking because... we're just friends helping each other....' That friendship would never [have] been born had it not been for the timebank. These people would never have met [if it] hadn't been for the timebank. And so, for me that's timebanking, it... connect[s] people" (Laura, Interview). Or as another coordinator-manager puts it, "[i]t's about maintaining the friendship... afterwards." (Sarah, FG1). In fact, in our interviews and focus groups we often found coordinatormanagers agreeing that in a future ideal case scenario their work-including the more formal features of timebanking (e.g. the registration of time credits, meeting with timebrokers, etc.)—would no longer be needed because the underlying values of timebanking would have spread across the community. Moreover, this emphasis on the values of timebanking helps coordinator-managers make sense of the formal diversity of timebanking practices across the county. As Michelle puts it, it is tempting to "get very bogged down with how everybody runs [their timebanks] completely differently". And yet she insists it shouldn't "really matter if they run differently, as long as the ethos is still there" (FG1).

However, when we look a bit more closely, we find that the 'nowhere but everywhere' paradox also indexes a set of tensions within the practice and discourse of timebanking, particularly as regards which timebanking values we end up emphasising or privileging. A review of the timebanking literature indicates how timebank advocates tend to stress how its practice seeks, in part, to contest the privatising tendencies of market logics that dominate social life. We thus see some contrasting possibilities emerge here, as regards the articulatory pathways available to coordinator-managers when engaging in exercises of ontopolitical interpretation. Take for example Laura's association of timebanking with friendship. This taps into an intuition about timebanking's values of co-operation, reciprocity, and a sense of belonging, even solidarity. However, an emphasis on friendship is perfectly compatible with privatisation tendencies. Quentin Skinner observes how 'prodigality' can 'be more leniently redescribed as liberality, avarice as carefulness, negligence as simplicity of mind' (Skinner in Howarth, 2010, 319). Likewise, timebanking can be rhetorically redescribed in ways that separate out some of its elements (community building, friendship ties) from others (creation of an alternative economy) while also stressing the former at the expense of the latter. In this view, competing onto-political interpretations can carry non-trivial critical implications, particularly when these take place in contexts more hostile to some of these elements than others. If, as here, the institution and expansion of the timebanking network is driven by funding imperatives to reduce isolation, this may exert extra pressure on managers to valorize the element of individual one-to-one friendships and their ameliorative effects, rather than other more collective and solidaristic elements that could contest market logics that produce isolation in the first place. Caren's idea to rebrand the approach in order to better reflect some elements rather than others, is rather telling: "We are possibly looking at a concept of 'favours' you know and looking at a 'mate' approach rather than, you know, banking and brokering 
and... all these [other] terminologies that become confusing for us" (Interview). ${ }^{1}$

In sum, we discern at least two ways the 'nowhere but everywhere' paradox indexes underlying tensions. First, timebanking's values are not recorded as such (nowhere), but are embodied in practice (everywhere); and second, some timebanking values are marginalized or excluded (nowhere), while others are emphasized and promoted (everywhere). We have already pointed out how dominant signifying frames and pressures can exacerbate tensions, ultimately blunting the potentially radical character of timebanking, and we will draw these aspects out more fully now in our concluding section.

\section{Concluding Discussion}

In this paper we have drawn on political discourse theory (PDT) to characterize and evaluate the tensions and challenges indexed by two paradoxes we identify in the management of one of the largest timebanking networks operating in the UK's voluntary sector, each of which can be linked to a more fundamental 'performance paradox'. In doing so, we contribute to organisation and critical management studies literature by extending the application of PDT to a new field (timebank and volunteer management); but we also contribute to the existing timebanking literature by foregrounding the discursive aspects of the political and ideological struggles involved in instituting and managing timebank volunteer practices. In our account we have found it helpful to consider the introduction of timebanking into the voluntary sector in terms of a 'primary' paradoxthe performance paradox of timebanking volunteer management-because the (rhetorical) performance of managers serves to bring into existence what s/he purportedly is supposed to manage. The two 'secondary' paradoxes we identify in our case study can thus be seen as emerging from, and overdetermining, this primary paradox.

An important aspect of our contribution involves casting coordinator-managers as discursive bricoleurs engaging in activities of rhetorical redescription and onto-political interpretation. Our case study presents a rich and detailed picture of this process of which we have presented only a snapshot in this paper. We show, in particular, how coordinator-managers can be both creative and pragmatic in their discursive performances, while at the same time highlighting how these discursive efforts run up against certain limits. We thus present a story about what happens

\footnotetext{
1 This terminological observation draws attention to an important strategic and tactical issue that would be interesting to explore in more depth, namely, to what extent is the very language timebanking advocates use risk readier cooptation by the market exchange signifying framework (e.g., time bank, time credits, time broker)?
}

when an alternative social economy-in this case, timebanking - is introduced into a context with powerful discursive frames and structural forces already in play.

Against the background of existing dominant structures and logics, timebanking can be understood as a counterlogic (Glynos \& Howarth, 2007) or counter-conduct (cf. Meriluoto, 2019). We can certainly try to negotiate new experiences and meanings associated with this counterlogic, but given the background context it is natural to expect confusions and tensions to arise. Moreover, there is always a danger that such counter-logics will be co-opted by already dominant signifying frames, as we appeal to familiar languages to make sense of new encounters, pulling those inchoate experiences into their orbit and blunting their radical potential. This is a story, therefore, about which of two logics will be victorious: the logics of cooptation or the logics of progressive transformation. The wider organisational and structural conditions can make it easier for counter-logics to emerge and thrive, but in our case study we found that these wider conditions and frames made it extremely challenging for the experiences and practices of timebanking to take root and achieve relative autonomy. Such organizational and structural conditions might include the hierarchical character of traditional volunteering charities often responsible for the institutionalisation of timebanking. They might include broader the politico-economic and policy conjuncture in which timebanking and volunteering meet, as exemplified by policy agendas like the UK's 'Big Society', in which the third sector was invited to fill the gaps created by austeritydriven cuts to the welfare state (Glynos \& Speed, 2012). Unfortunately, and despite the good intentions of many actors appearing in our narrative, our story is largely a story of cooptation. However, insofar as the signifying and structural pressures faced by discursive bricoleurs are not unique to our case study, the paradoxes we identify will also be relevant to volunteer management practices beyond those seeking to accommodate and promote timebanking.

As a final comment and to avoid misunderstanding: we are not suggesting that the virtues of timebanking should be promoted at the expense of other values, associated with traditional volunteering, the market, or the state. Our account simply seeks to take timebanking seriously as an alternative economy contender, showing how adopting its 'point of view' can reveal powerful lines of force that militate against new 'becomings', and thus perhaps to make it possible to acknowledge and strengthen the fragile process of 'pluralisation' inherent in existing ecologies of volunteering activities, some of which resonate more strongly with traditional volunteering and some of which resonate more strongly with timebank volunteering. 
Acknowledgements In developing the ideas informing this paper we have benefited enormously from the generous feedback we have received from many people, including colleagues at the Centre for Ideology and Discourse Analysis, University of Essex; at the Technologies of Governance Research Group, especially David Carter; and at the AlterEcos Research Group, Copenhagen Business School. We also thank the journal editors and reviewers for their feedback, and the special issue guest editors, in particular, for their very helpful and constructive comments.

\section{Declarations}

Conflict of Interest The authors have no conflicts of interest to declare that are relevant to the content of the article.

Ethical Approval All relevant ethical protocols have been followed in the conduct of research leading to the findings appearing in this article, including securing relevant consent from participants.

Open Access This article is licensed under a Creative Commons Attribution 4.0 International License, which permits use, sharing, adaptation, distribution and reproduction in any medium or format, as long as you give appropriate credit to the original author(s) and the source, provide a link to the Creative Commons licence, and indicate if changes were made. The images or other third party material in this article are included in the article's Creative Commons licence, unless indicated otherwise in a credit line to the material. If material is not included in the article's Creative Commons licence and your intended use is not permitted by statutory regulation or exceeds the permitted use, you will need to obtain permission directly from the copyright holder. To view a copy of this licence, visit http://creativecommons. org/licenses/by/4.0/.

\section{References}

Barnes, M. L., \& Sharpe, E. K. (2009). Looking beyond traditional volunteer management: A case study of an alternative approach to volunteer engagement in parks and recreation. VOLUNTAS: International Journal of Voluntary and Nonprofit Organizations, 20(2), 169-187.

Barron, P., \& Rihova, I. (2011). Motivation to volunteer: A case study of the Edinburgh International Magic Festival. International Journal of Event and Festival Management, 2(3), 202-217.

Booth, J. E., Park, K. W., \& Glomb, T. M. (2009). Employersupported volunteering benefits: Gift exchange among employers, employees, and volunteer organizations. Human Resource Management: Published in Cooperation with the School of Business Administration, the University of Michigan and in Alliance with the Society of Human Resources Management, 48(2), 227-249.

Boyle, D. (1999). Time as currency: A new approach to building communities. Voluntary Action- London Institute for Volunteering Research, 1, 25-38.

Boyle, D., \& Smith, K. (2005). SchooLets: An evaluation of the ippr project in its final year. New Economics Foundation.

Cahn, E. S. (2000). No more throw-away people: The co-production imperative. Essential Books.

Clemens, E. S., \& Cook, J. M. (1999). Politics and institutionalism: Explaining durability and change. Annual Review of Sociology, 25(1), 441-466.

Connolly, W. (1995). The Ethos of Pluralization, Minneapolis. University of Minnesota Press.

Connolly, W. (2010). A World of Becoming. Duke University Press.
Eliasoph, N. (2011). Making Volunteers: Civic life after welfare's end. Princeton University Press.

Feder, J., Howard, J., \& Schalon, W. (1992). Helping Oneself by Helping Others: Evaluation of a service credit banking demonstration. Journal of Aging \& Social Policy, 4(3), 111-138.

Fougère, M., Segercrantz, B., \& Seeck, H. (2017). A critical reading of the European Union's social innovation policy discourse:(Re) legitimizing neoliberalism. Organization, 24(6), 819-843.

Glynos, J., \& Howarth, D. (2007). Logics of critical explanation in social and political theory. Routledge.

Glynos, J., \& Speed, E. (2012). Varieties of co-production in public services: Time banks in a UK health policy context. Critical Policy Studies, 6(4), 402-433.

Glynos, J., \& Voutyras, S. (2022). Valuation studies and the cooptation charge: Quantification and monetization as political logics. Contemporary Political Theory. https://doi.org/10.1057/ s41296-021-00513-w.

Gregory, L. (2012). Local people rebuilding their communities: An exploration of Welsh time banking. Contemporary Wales, 25(1), 40-57.

Gregory, L. (2013). Improving health through participation: Time banks as a site for co-production. School of Social Sciences. Cardiff University.

Grubb, A., \& Henriksen, L. S. (2019). On the Changing Civic Landscape in Denmark and its Consequences for Civic Action. VOLUNTAS: International Journal of Voluntary and Nonprofit Organizations, 30(1), 62-73.

Howarth, D. (2010). Power, discourse, and policy: Articulating a hegemony approach to critical policy studies. Critical Policy Studies, 3(3-4), 309-335.

Jäger, U., Kreutzer, K., \& Beyes, T. (2009). Balancing acts: NPOleadership and volunteering. Financial Accountability \& Management, 25(1), 79-97.

Kreutzer, K., \& Jäger, U. (2011). Volunteering versus managerialism: Conflict over organizational identity in voluntary associations. Nonprofit and Voluntary Sector Quarterly, 40(4), 634-661.

La Cour, A. (2019). The management quest for authentic relationships in voluntary social care. Journal of Civil Society, 15(1), 1-17.

La Cour, A., \& Højlund, H. (2008). Voluntary social work as a paradox. Acta Sociologica, 51(1), 41-54.

Laclau, E. (1996). Emancipation(s). Verso.

Laclau, E., \& Mouffe, C. (1985). Hegemony and Socialist Strategy: Towards a Radical Democratic Politics. Verso.

Laclau, E., \& Mouffe, C. (1987). Post-Marxism without Apologies. New Left Review, 166(11-12), 79-106.

Lee, L. (2009). Valuing the time, leading the future: A case study of the time banking program of an educational institution in Taiwan. International NGO Journal, 4(6), 324-328.

Lewis, M. W. (2000). Exploring paradox: Toward a more comprehensive guide. Academy of Management Review, 25(4), $760-776$.

MacKillop, E. (2017). Leadership in organisational change: A poststructuralist research agenda. Organization, 25(2), 205-222.

Meriluoto, T. (2019). The will not to be empowered (according to your rules). Critical Social Policy, 39(1), 87-107.

Naughton-Doe, R., Cameron, A., \& Carpenter, J. (2020). Timebanking and the co-production of preventive social care with adults; what can we learn from the challenges of implementing personto-person timebanks in England? Health and Social Care in the Community, 00, 1-11.

North, P. (2003). Time Banks- Learning the lessons from LETS? Local Economy, 18(3), 267-270.

O'Toole, M., \& Grey, C. (2016). 'We can tell them to get lost, but we won't do that': Cultural control and resistance in voluntary work. Organization Studies, 37(1), 55-75. 
Omoto, A. M., Snyder, M., \& Martino, S. C. (2000). Volunteerism and the life course: Investigating age-related agendas for action. Basic and Applied Social Psychology, 22(3), 181-197.

Oppenheimer S. (2011). An Evaluation of Fair Shares Gloucester. Gloucester: Fair Shares.

Ozanne, L. (2010). Learning to exchange time: benefits and obstacles to time banking. International Journal of Community Currency Research 14.

Ryan-Collins, J., Stephens, L., \& Coote, A. (2008). The new wealth of time: How timebanking helps people build better public services. New Economics Foundation.

Salamon, L., \& Sokołowski, S. W. (2001). Volunteering in CrossNational Perspective: Evidence from 24 Countries. Johns Hopkins Center for Civil Society Studies.

Seyfang, G. (2002). Tackling social exclusion with community currencies: Learning from LETS to Time Banks. International Journal of Community Currency Research, 6(1), 1-11.

Seyfang, G. \& Smith, K. (2002). The Time of our Lives: using time banking for neighbourhood renewal and community capacity building. New Economics Foundation.
Smith, J. D. (2000). Volunteering and Social Development. Voluntary Action, 3(1), 9-23.

Smith, W. K., \& Lewis, M. W. (2011). Toward a theory of paradox: A dynamic equilibrium model of organizing. Academy of Management Review, 36(2), 381-403.

Warne, T. \& Lawrence, K. (2009). The Salford Time Banking Evaluation. A report for Unlimited Potential, formerly known as the Community Health Action Partnership (CHAP). Salford: The University of Salford.

Weatherbee, T., Dye, K., \& Mills, A. J. (2008). There's nothing as good as a practical theory: The paradox of management education. Management \& Organizational History, 3(2), $147-160$.

Yanay, G. V., \& Yanay, N. (2008). The decline of motivation?: From commitment to dropping out of volunteering. Nonprofit Management and Leadership, 19(1), 65-78.

Publisher's Note Springer Nature remains neutral with regard to jurisdictional claims in published maps and institutional affiliations. 